\title{
Dopa-Responsive Dystonia: Functional Analysis of Single Nucleotide Substitutions within the 5' Untranslated GCH1 Region
}

\author{
loanna A. Armata ${ }^{1 *}$, Leonora Balaj ${ }^{1 \oplus}$, John K. Kuster ${ }^{1}$, Xuan Zhang ${ }^{1}$, Shelun Tsai ${ }^{1}$, Andreas A. Armatas ${ }^{3}$, \\ Trisha J. Multhaupt-Buell ${ }^{1}$, Roy Soberman ${ }^{4}$, Xandra O. Breakefield ${ }^{1,2}$, Hiroshi Ichinose ${ }^{5}$, Nutan Sharma ${ }^{1}$ \\ 1 Department of Neurogenetics, Massachusetts General Hospital and Program in Neuroscience, Harvard Medical School, Boston, Massachusetts, United \\ States of America, 2 Department of Radiology, Massachusetts General Hospital and Program in Neuroscience, Harvard Medical School, Boston, \\ Massachusetts, United States of America, 3 Department of Biology, University of Patras, Rio Patras, Greece, 4 Renal Unit, Department of Medicine, \\ Massachusetts General Hospital, Boston, Massachusetts, United States of America, $\mathbf{5}$ Graduate School of Bioscience and Biotechnology, Tokyo Institute of \\ Technology, Yokohama, Japan
}

\begin{abstract}
Background: Mutations in the GCH1 gene are associated with childhood onset, dopa-responsive dystonia (DRD). Correct diagnosis of DRD is crucial, given the potential for complete recovery once treated with L-dopa. The majority of DRD associated mutations lie within the coding region of the $\mathrm{GCH} 1$ gene, but three additional single nucleotide sequence substitutions have been reported within the 5 ' untranslated (5'UTR) region of the mRNA. The biologic significance of these 5'UTR GCH1 sequence substitutions has not been analyzed.

Methodology/Principal Findings: Luciferase reporter assays, quantitative real time PCR and RNA decay assays, combined with bioinformatics, revealed a pathogenic 5'UTR GCH1 substitution. The +142C $>$ T single nucleotide 5'UTR substitution that segregates with affected status in DRD patients, substantially attenuates translation without altering RNA expression levels or stability. The $+142 \mathrm{C}>\mathrm{T}$ substitution disrupts translation most likely by creating an upstream initiation start codon (UAUG) and an upstream open reading frame (UORF).

Conclusions/Significance: This is the first $\mathrm{GCH} 1$ regulatory substitution reported to act at a post-transcriptional level, increasing the list of genetic diseases caused by abnormal translation and reaffirming the importance of investigating potential regulatory substitutions in genetic diseases.

Citation: Armata IA, Balaj L, Kuster JK, Zhang X, Tsai S, et al. (2013) Dopa-Responsive Dystonia: Functional Analysis of Single Nucleotide Substitutions within the 5' Untranslated GCH1 Region. PLoS ONE 8(10): e76975. doi:10.1371/journal.pone.0076975

Editor: Mark R. Cookson, National Institutes of Health, United States of America

Received January 11, 2012; Accepted September 5, 2013; Published October 4, 2013

Copyright: @ 2013 Armata et al. This is an open-access article distributed under the terms of the Creative Commons Attribution License, which permits unrestricted use, distribution, and reproduction in any medium, provided the original author and source are credited.

Funding: This work was supported by NIH/NINDS 5P50NS037409 (XOB and NS). The funders had no role in study design, data collection and analysis, decision to publish, or preparation of the manuscript.

Competing interests: The authors have declared that no competing interests exist.

*E-mail: ionarm999@gmail.com

๑ These authors contributed equally to this work.
\end{abstract}

\section{Introduction}

Dopa-responsive dystonia (DRD) was first described by Segawa et al. [1]. It is a movement disorder of childhood onset, typically beginning in a foot followed by spread, over several years, to involve other limbs, rendering walking difficult. DRD displays a diurnal fluctuation with increasing severity over the course of the day and a marked, sustained response to low therapeutic doses of levodopa. However, diagnosis remains a challenge with many cases being misdiagnosed as cerebral palsy or spastic diplegia.

DRD is frequently caused by heterozygous mutations in the guanosine triphosphate (GTP) cyclohydrolase 1 gene $(\mathrm{GCH} 1)$
$[2,3]$, with this form of dystonia now referred to as DYT5 [4]. GTP cyclohydrolase 1 catalyzes the first step in the biosynthesis of $(\mathrm{BH} 4)$. $\mathrm{BH} 4$ is a cofactor for three aromatic amino acid hydroxylases, including tyrosine hydroxylase (TH), which is the rate-limiting enzyme in dopamine biosynthesis [5]. Thus, low levels of $\mathrm{BH} 4$, due to mutations in the $\mathrm{GCH} 1$ gene, can lead to a reduction in dopamine synthesis and dysfunction of dopaminergic nigrostriatal neurochemical transmission [6].

To date, 114 different mutations have been identified in the GCH1 gene in patients with DRD (http://www.biopku.org/ authorisation/login.asp) involving, in their majority, missense and nonsense mutations in all 6 six exons [2,3,7-11], as well as large or multiexonic deletions and exon frameshifts [12-15]. 
$+1$

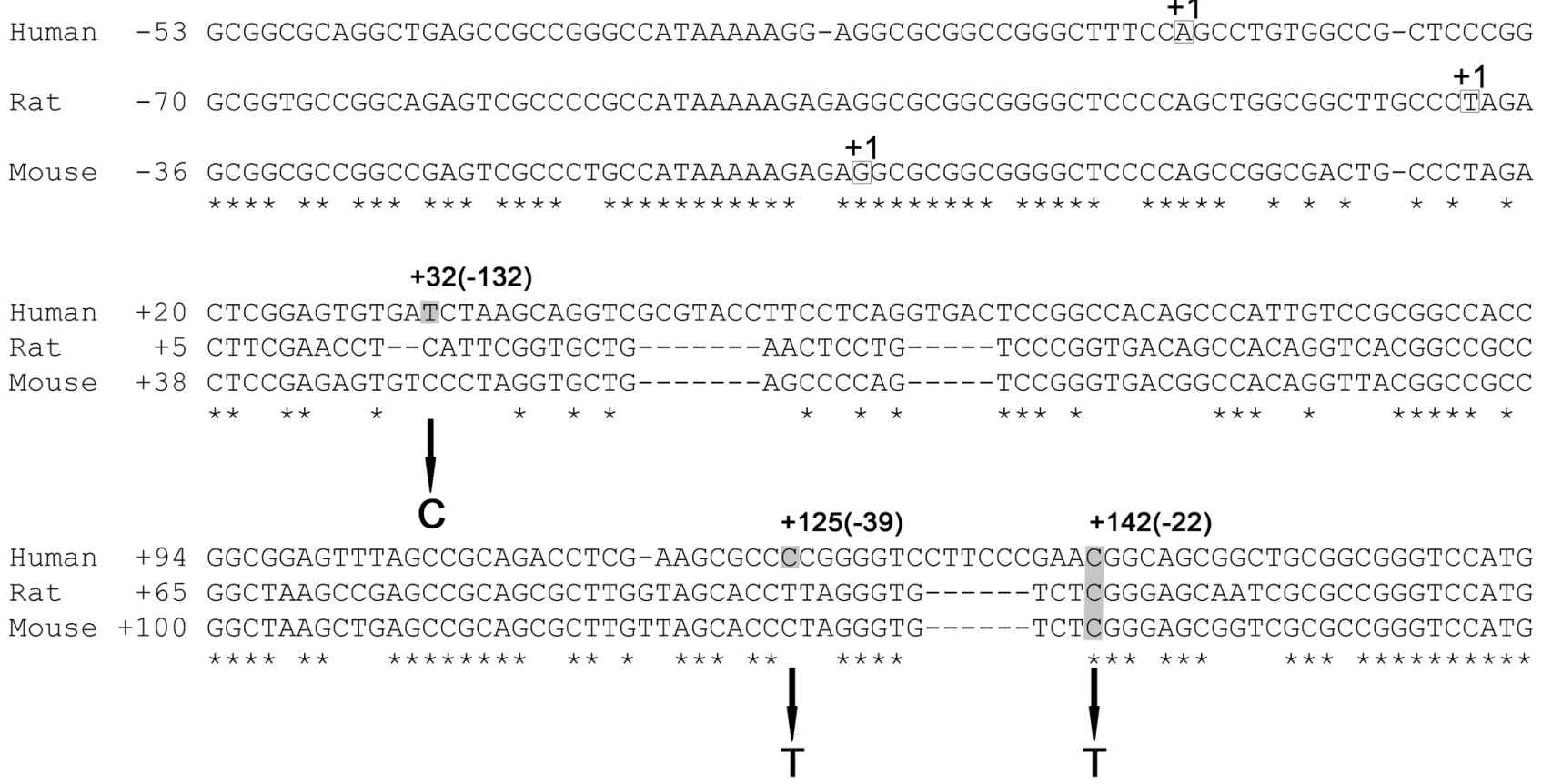

Figure 1. Alignment of the human, mouse and rat 5' upstream GCH1 regions. Nucleotides are numbered from the transcription start site $(+1)$ as previously identified for the human (top), rat (middle) and mouse (bottom) GCH1 genes. Position of each GCH1 5'UTR substitution identified to date is shaded and the nucleotide substitution is shown beneath the sequence. An asterisk $\left(^{*}\right)$ indicates sequence identity across the three species.

doi: 10.1371/journal.pone.0076975.g001

Noncoding GCH1 mutations have also been reported spanning its 5' upstream region [16-18] and intron-exon splice sites [19-21]. Within the 5' upstream region of the human $\mathrm{GCH} 1$ gene, three different single base pair (bp) substitutions have been identified at positions $-22 \mathrm{C}>\mathrm{T}[16,18],-39 \mathrm{C}>\mathrm{T}$ and $-132 \mathrm{~T}>\mathrm{C}$ [17], relative to the $\mathrm{GCH} 1$ translation start codon (ATG), in DRD individuals who lack mutations in the coding region (Figure 1). As the $\mathrm{GCH} 1$ transcription start site has been identified, we have now demarcated the substitutions relative to the $\mathrm{GCH} 1$ transcription start site $(+1)$ to be in accordance with revised genetic nomenclature. Thus, the $-22 \mathrm{C}>\mathrm{T}$ substitution is referred to as $+142 \mathrm{C}>\mathrm{T}$, the $-39 \mathrm{C}>\mathrm{T}$ as $+125 \mathrm{C}>\mathrm{T}$ and the $-132 \mathrm{~T}>\mathrm{C}$ as $+32 \mathrm{~T}>\mathrm{C}$. The $+125 \mathrm{C}>\mathrm{T}$ and $+32 \mathrm{~T}>\mathrm{C}$ substitutions were identified as co-existing in cis in a single subject with DRD [17], making it impossible to independently determine hereditary disease association for each substitution. The $+142 \mathrm{C}>\mathrm{T}$ substitution has been identified in two different reports, one of a single individual with DRD [16] and another in multiple generations of a family with DRD, in whom the $+142 \mathrm{C}>\mathrm{T}$ substitution segregated with affected status [18]. Whether any of these single nucleotide substitutions have an impact on $\mathrm{GCH} 1$ expression levels has not been investigated.

In the present paper, we demonstrated that among the three aforementioned 5'UTR GCH1 substitutions, only the $+142 \mathrm{C}>\mathrm{T}$ is a functional substitution that decreases protein expression. However, neither mRNA level nor stability were affected by this substitution. The 5'UTR mediated regulation of translation may reflect alterations in secondary RNA structure, changes in RNA binding motifs (RBPs) and associated proteins, or the creation of upstream open reading frames (uORFs) [22-25]. The $+142 \mathrm{C}>\mathrm{T}$ substitution within the GCH1 5'UTR introduces an upstream AUG (UAUG) that potentially creates an out-of-frame uORF. This UORF partially overlaps with the physiological ORF (pORF) and likely acts in a competitive manner to down regulate translation. To our knowledge, this is the first report of a translational disruption causing DRD or any other type of dystonia.

\section{Methods}

\section{Cell cultures}

The human neuroblastoma cell line SK-N-BE(2)-M17 was purchased from ATCC (Manassas, VA) and maintained in MEM/F-HAM, supplemented with $10 \%$ fetal bovine serum and $1 \%$ penicillin/streptomycin, at $37^{\circ} \mathrm{C}$ and $5 \% \mathrm{CO}_{2}$. Lymphocytes isolated from DRD patients and healthy individuals were Epstein Barr Virus (EBV) - transformed to stable cell lines, as previously described [26] and maintained in RPMI 1640 with $5 \%$ fetal calf serum, $1 \%$ penicillin/streptomycin and $2 \mathrm{mM}$ glutamine at $37^{\circ} \mathrm{C}$ and $5 \% \mathrm{CO}_{2}$.

\section{Patients and controls}

Lymphoblastoid cultures were established from 10 family members, spanning three generations, in whom the $+142 \mathrm{C}>\mathrm{T}$ substitution segregated with affected status [18]. Six subjects 
were heterozygous for the $+142 \mathrm{SNP}(\mathrm{C} / \mathrm{T})$ and met the clinical criteria for DRD [7], while the remaining four family members were homozygous for the $+142 \mathrm{C}$ nucleotide $(\mathrm{C} / \mathrm{C})$ and had no evidence of dystonia or other basal ganglia dysfunction on examination. Two additional control samples $(+142 \mathrm{C} / \mathrm{C})$ were utilized from the discarded sample collection of the Massachusetts General Hospital Neurogenetics DNA Diagnostic Laboratory. Full $\mathrm{GCH} 1$ gene sequencing (exons 1-6), including intron/exon junctions was performed for all samples and no other nucleotide changes were found [18]. The local institutional review board approved the study. All participants gave informed consent.

\section{Reporter constructs and mutagenesis}

Human $\mathrm{GCH} 1$ luciferase reporter constructs have been previously described [9]. We utilized a $615 \mathrm{bp}$ and a $5399 \mathrm{bp} \mathrm{5}$ upstream $\mathrm{GCH} 1$ fragment linked to the firefly luciferase (Fluc) cDNA in the promoter-less basic Picca Gene Basic Vector 2 (PGV-B2) (Toyo Ink Co., Ltd, Tokyo) [27] referred to as 615GCH1/WT (wild type) and 5399GCH1/WT, respectively (Figure 2A \& 2C). Mutant reporter constructs were generated from the parental $615 \mathrm{GCH} 1 / \mathrm{WT}$ by replacing the $+142 \mathrm{C}$ with a $\mathrm{T}(615 \mathrm{GCH} 1 /+142 \mathrm{~T})$, the $+125 \mathrm{C}$ with a $\mathrm{T}(615 \mathrm{GCH} 1 /+125 \mathrm{~T})$, the $+32 \mathrm{~T}$ with a $\mathrm{C}(615 \mathrm{GCH} 1 /+32 \mathrm{C})$, the $+125 \mathrm{C}$ with a $\mathrm{T}$ and the $+32 \mathrm{~T}$ with a $\mathrm{C}$ in the same construct $(615 \mathrm{GCH} 1 /+125 \mathrm{~T} /$ $+32 \mathrm{C}$ ) (Figure 2A). A mutant reporter construct was generated from the parental $5399 \mathrm{GCH} 1 / \mathrm{WT}$ by replacing the $+142 \mathrm{C}$ with a T (5399GCH1/+142T) (Figure 2C). All mutant products were generated using the QuikChange site-directed mutagenesis kit (Stratagene, La Jolla, CA) and appropriate sets of primers (sequences available upon request). All constructs were confirmed by DNA sequencing.

\section{Transfections and luciferase assays}

Transient transfections were performed using Lipofectamine 2000 (Invitrogen, Carlsbad, CA) in 1.0 to $1.5 \times 10^{6}$ cells/well plated onto 24-well tissue culture plates. For each Fluc reporter construct used in transfections, two independent plasmid Maxipreps (Qiagen, Valencia, CA) were used. Each transfection consisted of $0.8 \mu \mathrm{g}$ DNA of Fluc reporter construct and $0.4 \mu \mathrm{g}$ CMV-Renilla luciferase (Rluc) vector bearing Rluc under the cytomegalovirus (CMV) promoter, as an internal control of transfection efficiency (Promega, Madison, WI). Luciferase activity was analyzed $40 \mathrm{hrs}$ post-transfection, using a dual luciferase reporter kit (Promega) and a luminometer (Dynex, Richfield, NM). Luciferase assays were repeated at least four times, and within each experiment each construct was transfected in quadruplicate. Results were expressed as a mean of quadruplicate measures $( \pm$ S.E.M.) of Fluc normalized to Rluc activity. Statistical significance was determined by Student's t-test, comparing the activity of each mutant construct with the wild type parental construct.

\section{Quantitative real-time PCR}

RNA was isolated from SK-N-BE(2)-M17 cells transfected with the $615 \mathrm{GCH} 1 / \mathrm{WT}$ or the $615 \mathrm{GCH} 1 /+142 \mathrm{~T}$ construct or from $5.0 \times 10^{6}$ human lymphoblastoid cells using the miRNA purification kit (Qiagen) and then subjected to DNase treatment
(Qiagen). Two hundred ng of RNA was then reverse transcribed using Omniscript (Qiagen) and qPCR reactions were performed in a $25 \mu$ reaction mixture using Power SYBR® Green PCR Master Mix (Applied Biosystems, Foster City, CA) and $160 \mathrm{nM}$ of each primer. Amplification conditions consisted of: (1) 1 cycle of $50^{\circ} \mathrm{C}, 2 \mathrm{~min}$; (2) 1 cycle of $95^{\circ} \mathrm{C}, 10$ min; (3) 40 cycles of $95^{\circ} \mathrm{C}, 15 \mathrm{sec}$; and $60^{\circ} \mathrm{C}, 1 \mathrm{~min}$, and (4) 1 cycle of $95^{\circ} \mathrm{C}, 15 \mathrm{sec} ; 60^{\circ} \mathrm{C}, 20 \mathrm{sec}$; and $95^{\circ} \mathrm{C}, 15 \mathrm{sec}$, run on the $7000 \mathrm{ABI}$ Prism PCR system (Applied Biosystems). Fluc cycle threshold $(\mathrm{Ct})$ values were normalized to Rluc while the $\mathrm{GCH} 1 \mathrm{Ct}$ values were normalized to the housekeeping gene hypoxanthine phosphoribosyltransferase 1 (HPRT1). Normalized $\mathrm{Ct}$ values were then converted to relative mRNA levels. All qRT-PCRs were repeated 4 times for each gene and each sample was done in triplicate. Primer dimers were excluded by evaluation of dissociation curve and agarose gel electrophoresis. Primer sequences were as follows: Rluc forward- GATAACTGGTCCGCAGTGGT and reverse ACCAGATTTGCCTGATTTGC; fluc forwardATCCATCTTGCTCCAACACC TTTTCCGTCATCGTCTTTCC; CCTACTCGTCCATCCTGAGC GGACCTTTCCAACAAATGGA; TGACACTGGCAAAACAATGCA $\begin{array}{cr}\text { and } & \text { reverse } \\ \text { GCH1 } & \text { forward } \\ \text { and } & \text { reverse } \\ \text { HPRT1 } & \text { forward } \\ \text { and } & \text { reverse }\end{array}$ GGTCCTTTTCACCAGCAAAGCT. For mRNA decay assays, 24hrs post-transfection, SK-N-BE(2)-M17 cells were supplemented with ActinomycinD $(5 \mu \mathrm{M} / \mathrm{ml}$, Sigma-Aldrich, St. Louis, MO) and RNA was extracted at 0, 2, 4 and 6hrs while lymphoblastoid cultures were treated with ActinomycinD $(5 \mu \mathrm{M} / \mathrm{ml})$ for $0,6,12$ and $24 \mathrm{hrs}$. Normalized Ct values were converted to relative mRNA levels, set to $100 \%$ for $t=0$. Decay kinetics were obtained using linear regression analysis and the half life for each examined mRNA was calculated based on the slope and the intercept. The mRNA decay assays were repeated 3 times for each case, results were expressed as the mean \pm S.E.M. and statistical significance was determined using Student's t-test.

\section{Bioinformatics Analysis}

Alignment of the 5' upstream sequence of the human, mouse and rat $\mathrm{GCH} 1$ genomes was performed using ClustalW (http:// www.ebi.ac.uk/Tools/clustalw/). Prediction of RNA secondary structures within the human CFTR 5' UTR mRNA was performed using the mFold program, version 3.2 (http:// frontend.bioinfo.rpi.edu/applications/mfold/). The wild type (+142C) and +142T 5'UTR GCH1 sequences were also analyzed using the UTR site database (utrdb.ba.itb.cnr.it) to detect any RNA protein binding motifs created or destroyed by the $+142 \mathrm{C}>\mathrm{T}$ substitution. Finally, the 5'UTR-Fluc reporter sequences and the human $\mathrm{GCH} 1 \mathrm{mRNA}$ sequence (NM_000161.2) with either a $+142 \mathrm{C}$ or a $+142 \mathrm{~T}$ were analyzed on the NCBI ORF Finder (http://www.ncbi.nlm.nih.gov/projects/ gorf/) to detect potential uORFs.

\section{Results}

Alignment of the 5' upstream sequence of the human, mouse and rat $\mathrm{GCH} 1$ genes revealed that among the three point 
A

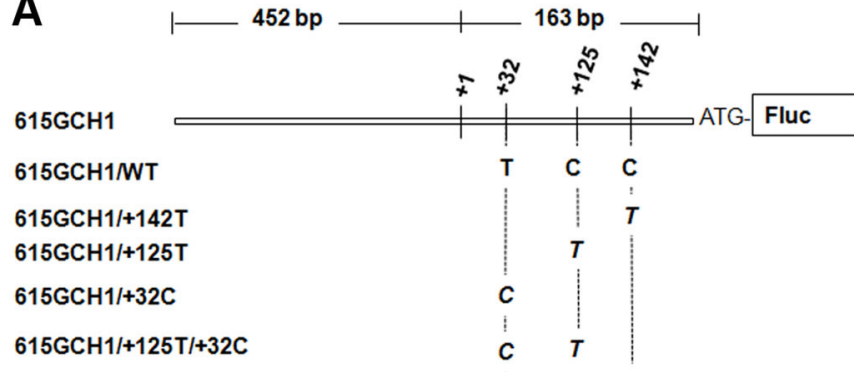

B

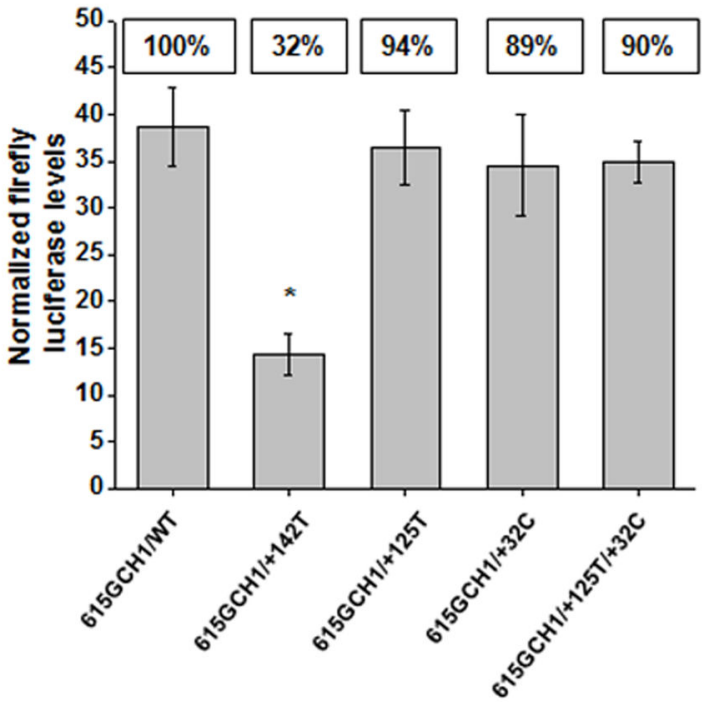

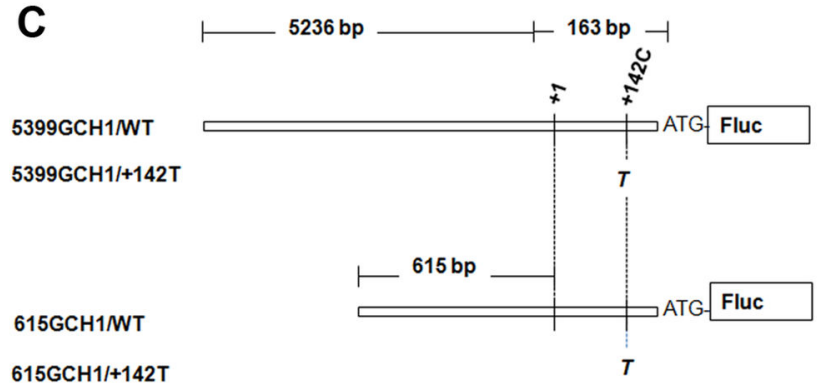

D

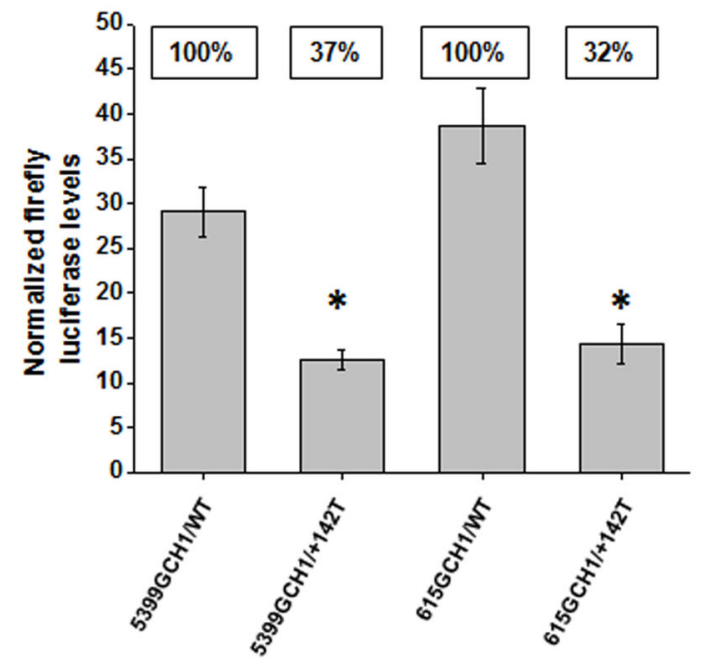

Figure 2. Effects of the $+142 \mathrm{C}>\mathrm{T}$, the $+125 \mathrm{C}>\mathrm{T}$ and the $+32 \mathrm{~T}>\mathrm{C} 5$ 'UTR $G \mathrm{CH}$ single nucleotide substitutions on luciferase activity. (A) Schematic representation of the luciferase reporter constructs bearing a 615 bp fragment of the $5^{\prime}$ upstream $\mathrm{GCH} 1$ region followed by the luciferase gene (Fluc) with either the wild type sequence $(+32 \mathrm{~T} /+125 \mathrm{C} /+142 \mathrm{C})$ or the identified substitutions $(+142 \mathrm{~T},+125 \mathrm{~T},+32 \mathrm{C}$ or $+32 \mathrm{C} /+125 \mathrm{~T})$. (B) SK-N-BE2-M17 cells were transiently transfected with each Fluc construct indicated in the bottom of each graph bar and the CMV-Rluc. Results are shown as the mean \pm S.E.M. of relative Fluc normalized to Rluc activity. The $\%$ activity of each construct relative to the wild type (set as $100 \%)$ is indicated above each bar $(n=4$, Student's t-test * $=$ $P \leq 0.005$ ). (C) Schematic representation of the reporter constructs bearing a 5399 or a 615 bp fragment of the 5' upstream GCH1 region followed by the Fluc with either a C $(5399 \mathrm{GCH} 1 / \mathrm{WT}$ and $615 \mathrm{GCH} 1 / \mathrm{WT})$ or a T $(5399 \mathrm{GCH} 1 /+142 \mathrm{~T}$ and $615 \mathrm{GCH} 1 /+142 \mathrm{~T})$ at +142. (D SK-N-BE2-M17 cells were transiently transfected with each Fluc construct indicated in the bottom of each graph bar and the CMV-Rluc. Results are shown as the mean \pm S.E.M. of relative Fluc normalized to Rluc activity. The \% activity of each construct relative to the wild type (set as $100 \%)$ is indicated above each bar $\left(n=4\right.$, Student's t-test $\left.{ }^{*}=P \leq 0.005\right)$.

doi: 10.1371/journal.pone.0076975.g002

substitutions examined only the $+142 \mathrm{C}$ is evolutionarily conserved between the human, rat and mouse genome (Figure 1). All of the three 5 ' upstream $\mathrm{GCH} 1$ substitutions fall within its 5'UTR (+142C>T; $+125 \mathrm{C}>\mathrm{T}$; $+32 \mathrm{~T}>\mathrm{C}$; Figure 1) rendering it more likely that any potential effects would involve posttranscriptional mechanisms.

\section{Effects of the GCH1 5'UTR substitution on the luciferase reporter assay}

We utilized a previously characterized $\mathrm{GCH} 1$ reporter construct [27] encompassing 452 bps upstream of the transcription start site $(+1)$ and 163 bps corresponding to the distance between the +1 and the translation start site ATG (615GCH1/WT; Figure 2A). Three mutant reporter constructs were generated to mimic the 5'UTR GCH1 reported substitutions; $615 \mathrm{GCH} 1 /+142 \mathrm{~T}, \quad 615 \mathrm{GCH} 1 /+125 \mathrm{~T}$ and $615 \mathrm{GCH} 1 /+32 \mathrm{C}$ (Figure 2A). Transient transfection assays were performed in a human neuroblastoma SK-N-BE(2)-M17 cell line, a monoamine (MA) and $\mathrm{BH} 4$ containing cell line in which the $\mathrm{GCH} 1$ promoter has been reported to be active [28]. Normalized Fluc activity for each of the mutant constructs compared to the wild type (set at $100 \%$ ) revealed that the $615 \mathrm{GCH} 1 /+142 \mathrm{~T}$ construct caused a reduction in luciferase activity to $32 \%$ of the $615 \mathrm{GCH} 1 / \mathrm{WT}$ activity $(\mathrm{n}=4, P \leq 0.005$; 
A

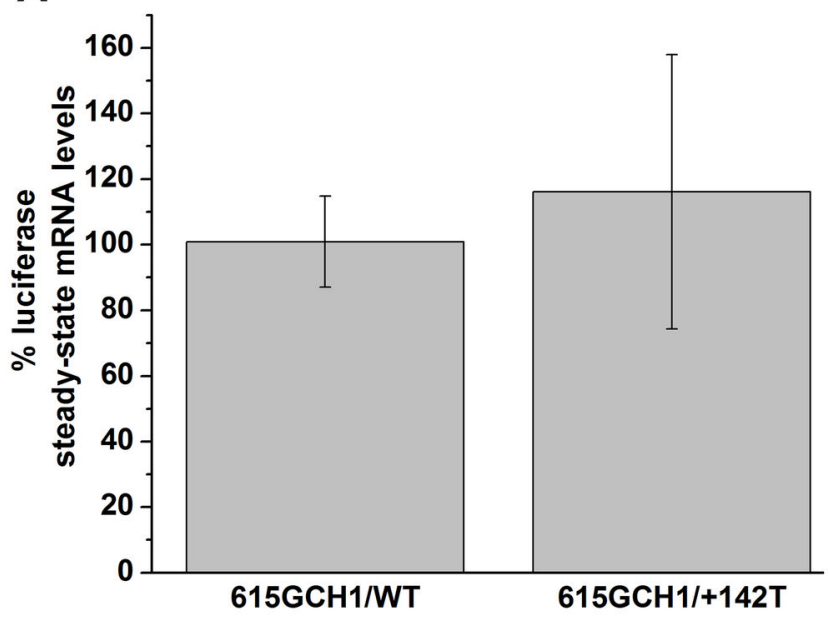

B

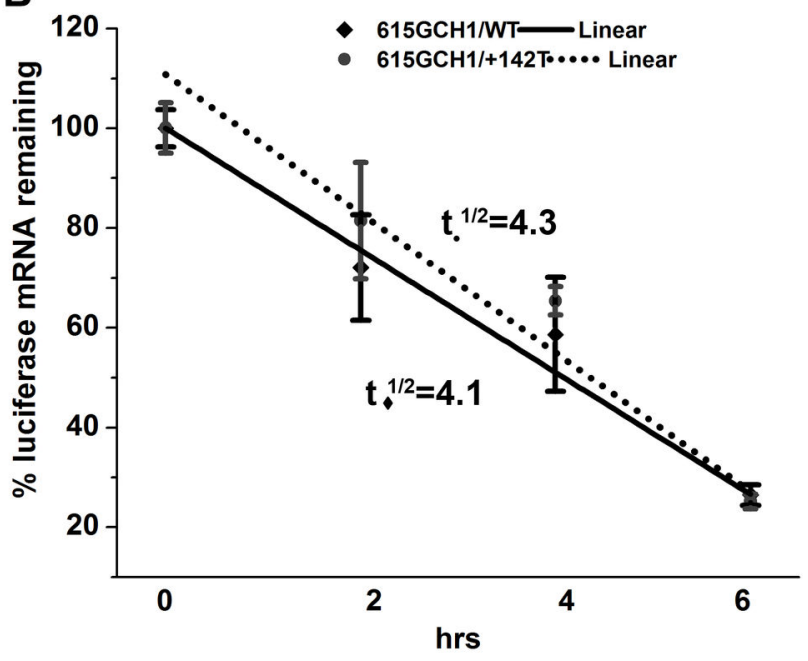

Figure 3. Effects of the $+142 \mathrm{C}>\mathrm{T}$ GCH1 substitution on the steady-state luciferase mRNA level and its stability. (A) Steadystate levels of Fluc/Rluc mRNA in SK-N-BE2-M17 cells transiently transfected with either the 615GCH1/WT or 615GCH1/+142T Fluc and the CMV-Rluc construct. Normalized Fluc Ct values were converted to relative mRNA levels and results are shown as mean \pm S.E.M $(615 G C H 1 /$ WT, set at $100 \%)(n=4)$. (B) SK-N-BE2-M17 cells were transiently transfected as above and treated with ActinomycinD. RNA was collected at $0,2,4$ and $6 \mathrm{hrs}$ and subjected to qRT-PCR. Normalized Fluc Ct values were converted to relative mRNA levels and results are shown as means \pm S.E.M. plotted to a linear regression over time, with time zero set to $100 \%$. Half-lives were calculated based on the slope and intercept; $t_{+}^{1 / 2}=4.1 \mathrm{hrs}$ for the $615 \mathrm{GCH} 1 / \mathrm{WT}$ construct and $\mathrm{t}^{1 / 2}=4.3 \mathrm{hrs}$ for the $615 \mathrm{GCH} 1 /+142 \mathrm{~T}$ construct $(\mathrm{n}=3)$.

doi: 10.1371/journal.pone.0076975.g003

Figure 2B). Likewise, when the $+142 \mathrm{~T}$ substitution was introduced in the larger 5399 bp reporter construct (5399GCH1/WT and 5399GCH1/+142T, Figure 2C) luciferase activity dropped to $37 \%$ of the wild type $(n=4, P \leq 0.005$; Figure 2D). In contrast, the $615 \mathrm{GCH} 1 /+125 \mathrm{~T}$, the $615 \mathrm{GCH} 1 /+32 \mathrm{C}$ and the double mutant $615 \mathrm{GCH} 1 /+125 \mathrm{~T} /+32 \mathrm{C}$ constructs did not result in a statistically significant reduction in luciferase activity (94\%, $89 \%$ and $90 \%$ of wild type activity, respectively, $n=4$; Figure 2B). Finally, after generation of the $+142 \mathrm{~T}$ reporter construct, we re-introduced the $+142 \mathrm{C}$ in the $5399 \mathrm{GCH} 1 /+142 \mathrm{~T}$ or the $615 \mathrm{GCH} 1 /+142 \mathrm{~T}$ constructs and luciferase activity returned to wild type levels (data not shown).

\section{Effects of the +142C>T GCH1 substitution on luciferase mRNA}

We then analyzed the effects of the $+142 \mathrm{C}>\mathrm{T}$ substitution on luciferase mRNA levels expressed in SK-N-BE(2)-M17 cells transiently transfected with luciferase reporter constructs. QRTPCRs revealed no statistically significant differences between the relative mRNA levels of the $615 \mathrm{GCH} 1 / \mathrm{WT}$ (set to $100 \%$ ) and the $615 \mathrm{GCH} 1 /+142 \mathrm{~T}(113 \%)$ reporter constructs $(n=4$; Figure $3 \mathrm{~A}$ ). To determine if the $+142 \mathrm{C}>\mathrm{T}$ substitution affected mRNA stability, inhibition of transcription was achieved with ActinomycinD and luciferase mRNA half-lives were determined to $4.1 \mathrm{hrs}$ for the $615 \mathrm{GCH} 1 / \mathrm{WT}$ and $4.3 \mathrm{hrs}$ for the $615 \mathrm{GCH} 1 /+142 \mathrm{~T}$ transcript. This difference in half-lives was not statistically significant ( $n=3$, Figure 3B).

\section{Endogenous GCH1 levels in normal individuals and DRD patients}

We further investigated the effects of the $+142 \mathrm{C}>\mathrm{T}$ substitution on in vivo GCH1 mRNA levels by qRT-PCR analysis in lymphoblastoid cultures established from DRD patients and control individuals. While the average relative steady-state levels of GCH1 mRNA were lower in DRD patients (0.842) compared to controls (set at 1.0), this reduction was not statistically significant $(n=4$; Figure $4 A$ ). Furthermore, when transcription was inhibited by actinomycinD, there was no statistically significant difference in the $\mathrm{GCH} 1$ transcript half-life between DRD and control subjects (11.4 hrs in controls vs 11.8 hrs in patients), (n=3; Figure 4B).

\section{Bioinformatics analysis}

RNA secondary structures analysis, performed for the complete 5'UTR GCH1 region with either a C or a $\mathrm{T}$ at +142 predicted no structural differences between them (Figure 5). Since our experimental data did not reveal evidence for transcriptional effects of the $+142 \mathrm{C}>\mathrm{T}$ substitution, we scanned the wild type $\mathrm{GCH} 1+142 \mathrm{C}$ and the $\mathrm{GCH} 1+142 \mathrm{~T}$ 5'UTRs for RBP motifs and found no differences (data not shown). However, we observed that the $+142 \mathrm{C}>\mathrm{T}$ substitution created a novel upstream ATG codon (ACG>ATG) (Figure 6). Indeed, scanning the 5'UTR-coding $\mathrm{GCH} 1$ sequence with the $\mathrm{NCBI}$ ORF Finder software revealed that in presence of a $T$ at +142 , an UATG arises and a potential upstream open reading frame (uORF) (sequence in bold; Figure 6), starting 23 nucleotides 
A

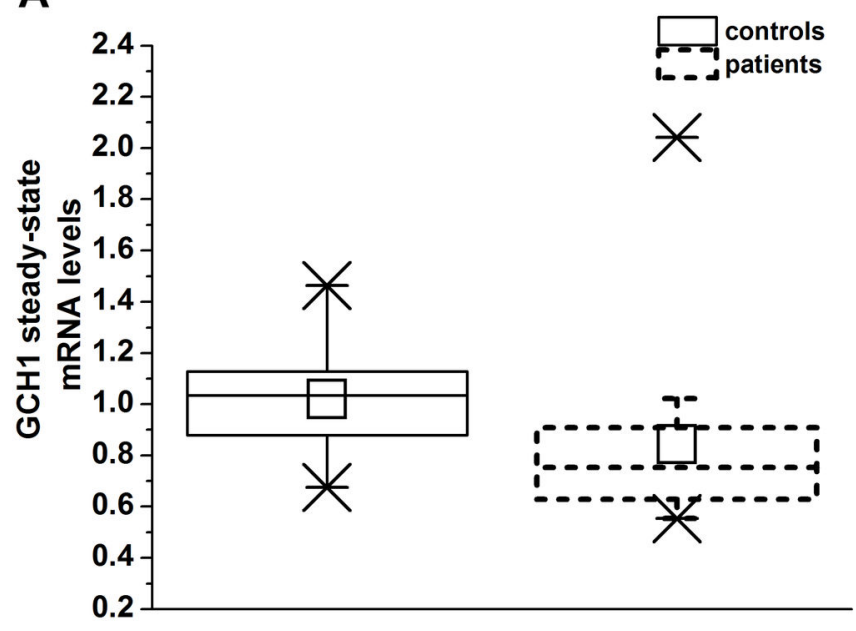

B

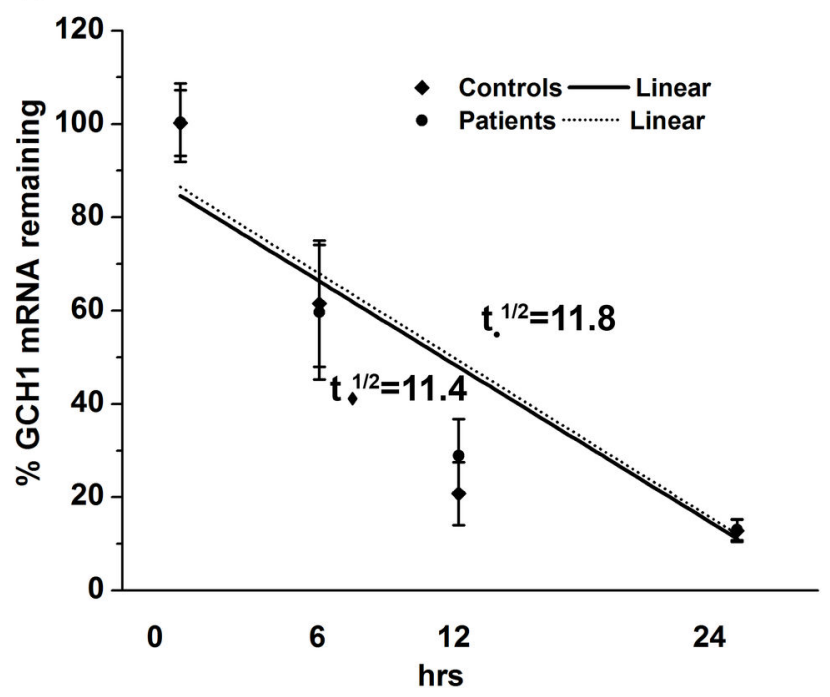

Figure 4. GCH1 mRNA levels and stability in lymphoblastoid cells from DRD and control subjects. (A) Steady-state levels of GCH1 mRNA in lymphoblastoid cells derived from six DRD subjects and six control subjects. Normalized GCH1 Ct values were converted to relative mRNA levels. Box plots show mean \pm S.E.M. of the control and DRD GCH1 mRNA levels ( $n=4)$. (B) Lymphoblastoid cultures from DRD and control subjects were exposed to ActinomycinD, RNA was collected at $0,6,12$ and 24 hrs and subjected to qRT-PCR. Normalized GCH1 Ct values were converted to relative mRNA levels and results are shown as means \pm S.E.M. plotted to a linear regression over time, with time zero set at $100 \%$. Half-lives were calculated based on the slope and intercept; $\mathrm{t}^{1 / 2}=11.4 \mathrm{hrs}$ for control and $\mathrm{t}^{1 / 2}=11.8 \mathrm{hrs}$ for DRD subjects $(\mathrm{n}=3)$.

doi: 10.1371/journal.pone.0076975.g004

upstream of the physiological ATG (underlined; Figure 6) and terminating after 219 bases at a STOP codon within an exon of the wild type GCH1 sequence (TGA circled; Figure 6). Thus, the $+142 \mathrm{C}>\mathrm{T}$ substitution is likely to result in production of a 73 amino acid peptide (MAAAAAGPWRRALCGHRRRSRGAPGAAMGSPSGIRRGPG PAGRRRSPRGPRPRARSPRTAGRASGPAARRITS) which is out of frame with the PATG codon initiating translation of the physiological GCH1 protein (Figure 6). Note that for the 5'UTR GCH1-luciferase constructs used in this study, sequence scanning by the NCBI ORF Finder software showed that the newly generated uORF would encode an out of frame of 14aa truncated peptide (analysis non shown).

\section{Discussion}

In eukaryotes, regulation of protein synthesis is a finelytuned process involving multiple steps of transcription, posttranscriptional processing and modification, mRNA stability, translation initiation and posttranslational modification. Human disease can result from single nucleotide polymorphisms that affect any step of this finely tuned regulatory system. In particular for diseases linked to noncoding substitutions, functional assays are required to establish a link between the substitution and the disease phenotype. In DRD, three different sequence substitutions have been identified within the 5 ' untranslated region of the $\mathrm{GCH} 1$ gene [16-18]. We demonstrated here that the $+125 \mathrm{C}>\mathrm{T}$ and the
$+32 \mathrm{~T}>\mathrm{C}$ substitutions reported together in a single DRD patient had negligible effects on luciferase activity when tested either individually or combined into a single reporter construct. The presence of these substitutions has been examined in only 3 neurologically normal subjects, who did not harbor either or both substitutions [17]. In contrast, the $+142 \mathrm{C}>\mathrm{T}$ substitution which segregates with affected status in ten members of a single DRD family, spanning three generations but not found in a total of 543 control alleles [18], had a strong negative effect, leading to a $68 \%$ reduction in luciferase activity. The effect persisted even when the $+142 \mathrm{~T}$ substitution was introduced into the larger $5399 \mathrm{GCH} 1$ reporter construct having a greater degree of endogenous transcriptional regulation. To ensure that no random mutations within the luciferase vector backbone affected our results, we re-introduced the wild type $+142 \mathrm{C}$ back onto the mutant $+142 \mathrm{~T}$ construct and luciferase activity returned to wild type levels. To our knowledge, no gene dosages studies of the $+142 \mathrm{C}>\mathrm{T}$ substitution carriers has been conducted.

We next investigated if the $+142 \mathrm{~T}$-triggered reduction in luciferase activity was mediated by a reduction in luciferase mRNA levels. We found that the $+142 \mathrm{~T}$ had no significant effect on luciferase mRNA abundance. Furthermore, RNA decay kinetics demonstrated a similar mRNA half-life for both the $+142 \mathrm{C}$ and the $+142 \mathrm{~T}$ 5'UTR luciferase reporter constructs. Similarly, there was no statistically significant difference in endogenous steady-state GCH1 mRNA levels or its stability in lymphoblastoid cells derived from DRD and control subjects. 


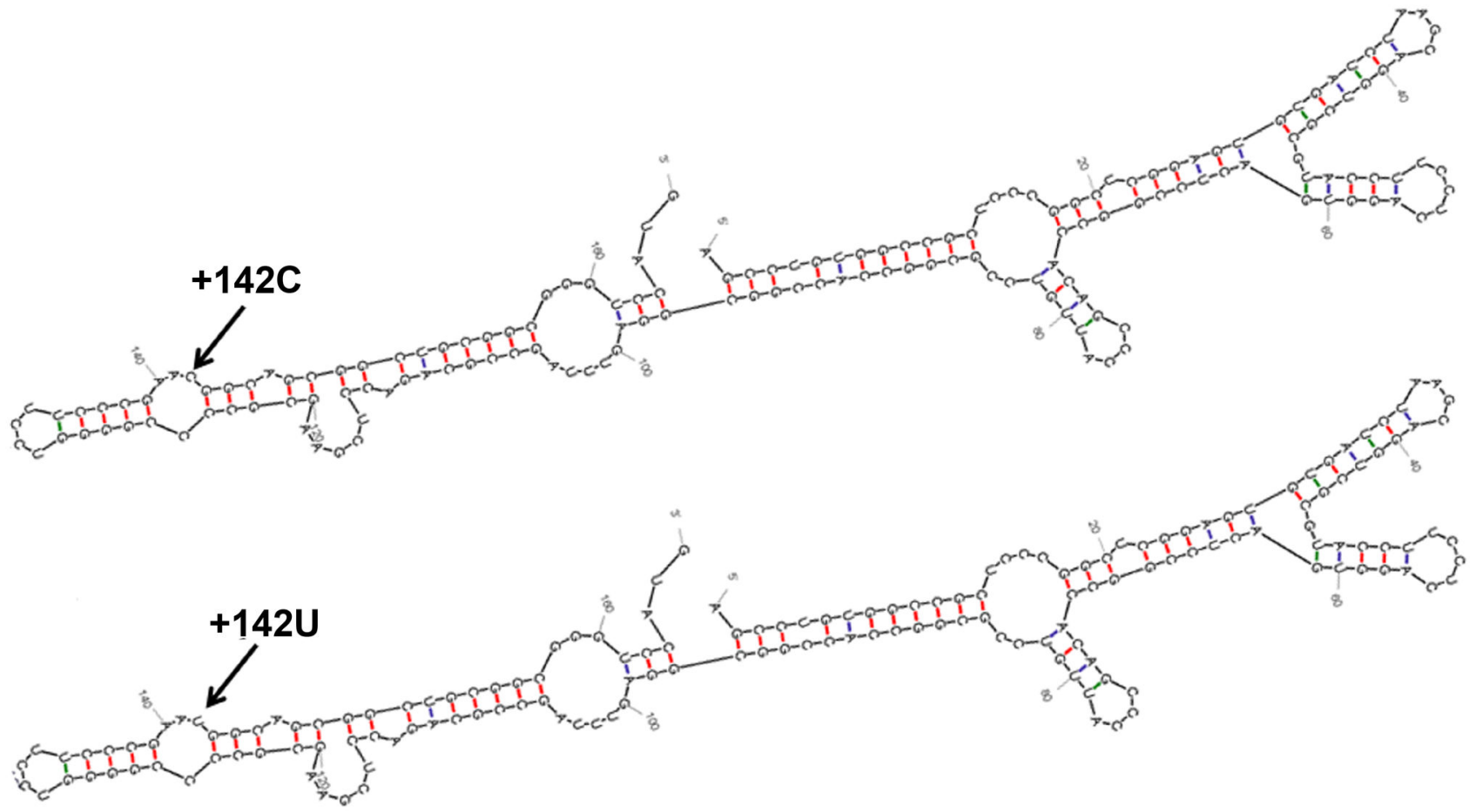

Figure 5. Computer-assisted RNA secondary structures for the +142C and the +142T GCH1 5 upstream region. Mfold analysis predicted same RNA secondary structure regardless of a +142C (up) or a +142T (bottom) within the GCH1 5'UTR. The position of the $+142 \mathrm{C}>\mathrm{T}$ substitution is indicated with an arrow.

doi: 10.1371/journal.pone.0076975.g005

Cerebrospinal fluid from these patients was not available to assess the $\mathrm{BH}_{4}$ level but previous studies support that altered GCH1 mRNA levels can be detected in mononuclear blood cells from DRD patients with coding GCH1 mutations [29]. In agreement with our experimental data, bioinformatics analysis predicted the same RNA structure in the presence of a $+142 \mathrm{C}$ or a $+142 \mathrm{~T}$ within the GCH1 5'UTR. Taken together these results support that the $+142 \mathrm{C}>\mathrm{T}$ GCH1 5 'UTR substitution alters efficiency of translation without affecting RNA levels or RNA stability/structure.

Scanning of the wild type $+142 \mathrm{C}$ and the $+142 \mathrm{~T} \mathrm{GCH1} 5^{\circ}$ UTR sequences predicted no differences in RBP sites. Thus, it is unlikely that differences between RBP association with the wild type and the 142T 5'UTR sequences are the cause of the observed changes in translation. An alternate level of translational regulation involves the creation of UAUGs and uORFs [25]. Genes can be devoid of UAUGs or bear a single or several UAUGs which mediate complete or partial inhibition of the physiological AUG (pAUG) $[22,25,30]$. Our in silico analysis revealed that the wild type 5'UTR $\mathrm{GCH} 1$ region lacks of any uAUG. However, the $+142 T$ substitution introduces a single
UAUG and a potential uORF encoding a truncated, out of frame, peptide. The $+142 \mathrm{~T}$ substitution results in reduced luciferase activity indicating that both the truncated and full length luciferase protein are generated, with the truncated peptide competing for efficiency of translation against the full length peptide.

These results do not provide direct evidence of the effects of the $+142 \mathrm{~T}$ substitution on the GCH1 levels in DRD patients. However, similar to the luciferase constructs, the $+142 \mathrm{~T}$ may generate an UORF that encodes a 73 aa out of frame peptide that competes with the translation of wild type $\mathrm{GCH} 1$ initiated by the pAUG. A model in which a mixture of wild type and truncated peptides are generated in a competitive manner due to creation of novel UAUGs has been reported in human diseases ranging from a predisposition to cancer [31] to bronchiectasis [32] and bipolar depression [33]. Our study expands this list to include dystonia by revealing that the $+142 \mathrm{C}>\mathrm{T}$ GCH1 5'UTR substitution detected in DRD patients is a functional mutation that reduces translational efficiency and likely leads to reduced wild type $\mathrm{GCH} 1$ protein levels, underlying manifestation of DRD. 


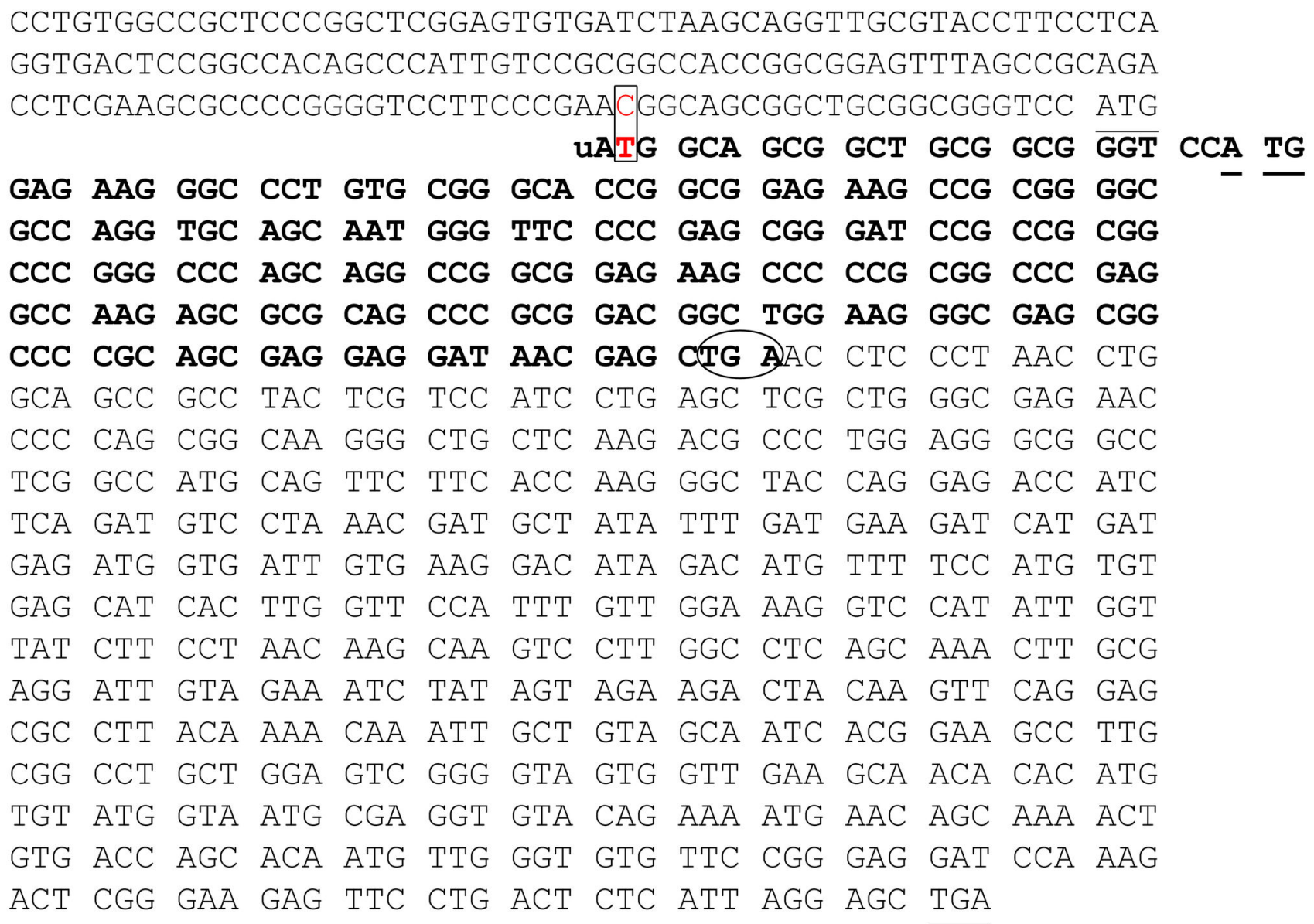

Figure 6. The GCH1 5'UTR and Coding region. Normal translation starts at the underlined ATG and ends at the underlined TGA stop codon. The rectangle indicates the point of the $+142 \mathrm{C}>\mathrm{T}$ substitution and the bases in bold indicate the out of frame $u O R F$ initiated by the UATG and ending at a TGA triplet (bold, circled) within the coding region of the normal sequence.

doi: 10.1371/journal.pone.0076975.g006 


\section{Acknowledgments}

We thank Ms. Suzanne McDavitt for skilled editorial assistance, Sarada Sivaraman for help with the RNA isolation and Mary Anne Anderson for establishing the lymphoblastoid cultures.

\section{Author Contributions}

Conceived and designed the experiments: IAA LB XOB HI NS. Performed the experiments: IAA LB JK ST AAA XZ. Analyzed the data: IAA LB JK ST AAA RS. Contributed reagents/ materials/analysis tools: HI RS TJMB. Wrote the manuscript: IA XOB NS.

\section{References}

1. Segawa M, Hosaka A, Miyagawa F, Nomura Y, Imai H (1976) Hereditary progressive dystonia with marked diurnal fluctuation. Adv Neurol 14: 215-233. PubMed: 945938.

2. Ichinose H, Ohye T, Takahashi E, Seki N, Hori T et al. (1994) Hereditary progressive dystonia with marked diurnal fluctuation caused by mutations in the GTP cyclohydrolase I gene. Nat Genet 8: 236-242. doi:10.1038/ng1194-236. PubMed: 7874165 .

3. Hagenah J, Saunders-Pullman R, Hedrich K, Kabakci K, Habermann K et al. (2005) High mutation rate in dopa-responsive dystonia: detection with comprehensive GCHI screening. Neurology 64: 908-911. doi: 10.1212/01.WNL.0000152839.50258.A2. PubMed: 15753436

4. Brüggemann N, Klein C (2010) Genetics of primary torsion dystonia. Curr Neurol Neurosci Rep 10: 199-206. doi:10.1007/ s11910-010-0107-5. PubMed: 20425035.

5. Ichinose H, Nomura T, Sumi-Ichinose C (2008) Metabolism of tetrahydrobiopterin: its relevance in monoaminergic neurons and neurological disorders. Chem Rec 8: 378-385. doi:10.1002/tcr.20166. PubMed: 19107867

6. Segawa M (2011) Hereditary progressive dystonia with marked diurnal fluctuation. Brain Dev 33: 195-201. doi:10.1016/j.braindev.2010.10.015. PubMed: 21094587

7. Nygaard TG, Marsden CD, Duvoisin RC (1988) Dopa-responsive dystonia. Adv Neurol 50: 377-384. PubMed: 3041760.

8. Witter K, Werner T, Blusch JH, Schneider EM, Riess O et al. (1996) Cloning, sequencing and functional studies of the gene encoding human GTP cyclohydrolase I. Gene 171: 285-290. doi: 10.1016/0378-1119(95)00886-1. PubMed: 8666288.

9. Ichinose H, Ohye T, Matsuda Y, Hori T, Blau N et al. (1995) Characterization of mouse and human GTP cyclohydrolase I genes. Mutations in patients with GTP cyclohydrolase I deficiency. J Biol Chem 270: 10062-10071. doi:10.1074/jbc.270.17.10062. PubMed: 7730309

10. Bonafé L, Thöny B, Leimbacher W, Kierat L, Blau N (2001) Diagnosis of dopa-responsive dystonia and other tetrahydrobiopterin disorders by the study of biopterin metabolism in fibroblasts. Clin Chem 47: 477-485. PubMed: 11238300

11. Ichinose H, Inagaki H, Suzuki T, Ohye T, Nagatsu T (2000) Molecular mechanisms of hereditary progressive dystonia with marked diurnal fluctuation, Segawa's disease. Brain Dev 22 Suppl 1: S107-S110. doi: 10.1016/S0387-7604(99)00126-6. PubMed: 10984669.

12. Klein C, Hedrich K, Kabakçi K, Mohrmann K, Wiegers K et al. (2002) Exon deletions in the GCHI gene in two of four Turkish families with dopa-responsive dystonia. Neurology 59: 1783-1786. doi: 10.1212/01.WNL.0000035629.04791.3F. PubMed: 12473771.

13. Wu-Chou YH, Yeh TH, Wang CY, Lin JJ, Huang CC et al. (2010) High frequency of multiexonic deletion of the $\mathrm{GCH} 1$ gene in a Taiwanese cohort of dopa-response dystonia. Am J Med Genet B Neuropsychiatr Genet 153B: 903-908. PubMed: 20082337.

14. Steinberger D, Trübenbach J, Zirn B, Leube B, Wildhardt $G$ et al. (2007) Utility of MLPA in deletion analysis of GCH1 in dopa-responsive dystonia. Neurogenetics 8: 51-55. doi:10.1007/s10048-006-0069-6. PubMed: 17111153

15. Tachi N, Takahashi $S$, Jo $M$, Shinoda M (2011) A new mutation of $\mathrm{GCH} 1$ in triplets family with dopa-responsive dystonia. Eur J Neurol 18: 1191-1193. doi:10.1111/j.1468-1331.2011.03354.x. PubMed: 21834904.

16. Tassin J, Durr A, Bonnet AM, Gil R, Vidailhet M et al. (2000) Levodoparesponsive dystonia. GTP cyclohydrolase I or parkin mutations? Brain 123(6): 1112-1121. doi:10.1093/brain/123.6.1112.

17. Bandmann O, Valente EM, Holmans $P$, Surtees RA, Walters JH et al. (1998) Dopa-responsive dystonia: a clinical and molecular genetic study. Ann Neurol 44: 649-656. doi:10.1002/ana.410440411. PubMed: 9778264.

18. Sharma N, Armata IA, Multhaupt-Buell TJ, Ozelius LJ, Xin W et al. (2011) Mutation in $5^{\prime}$ upstream region of $\mathrm{GCH}$ gene causes familial dopa-responsive dystonia. Mov Disord 26: 2140-2141. doi:10.1002/ mds.23786. PubMed: 21674621.

19. Hirano M, Imaiso $Y$, Ueno S (1997) Differential splicing of the GTP cyclohydrolase I RNA in dopa-responsive dystonia. Biochem Biophys Res Commun 234: 316-319. doi:10.1006/bbrc.1997.6632. PubMed: 9177267.

20. Weber Y, Steinberger D, Deuschl G, Benecke R, Müller U (1997) Two previously unrecognized splicing mutations of $\mathrm{GCH} 1$ in Doparesponsive dystonia: exon skipping and one base insertion. Neurogenetics 1: 125-127. doi:10.1007/s100480050018. PubMed: 10732814.

21. Nishiyama N, Yukishita S, Hagiwara H, Kakimoto S, Nomura $Y$ et al. (2000) Gene mutation in hereditary progressive dystonia with marked diurnal fluctuation (HPD), strictly defined dopa-responsive dystonia. Brain Dev 22 Suppl 1: S102-S106. doi:10.1016/ S0387-7604(99)00124-2. PubMed: 10984668.

22. Calvo SE, Pagliarini DJ, Mootha VK (2009) Upstream open reading frames cause widespread reduction of protein expression and are polymorphic among humans. Proc Natl Acad Sci U S A 106: 7507-7512. doi:10.1073/pnas.0810916106. PubMed: 19372376.

23. Jackson RJ, Hellen CU, Pestova TV (2010) The mechanism of eukaryotic translation initiation and principles of its regulation. Nat Rev Mol Cell Biol 11: 113-127. doi:10.1038/nrm2838. PubMed: 20094052.

24. Sonenberg N, Hinnebusch AG (2009) Regulation of translation initiation in eukaryotes: mechanisms and biological targets. Cell 136: 731-745. doi:10.1016/j.cell.2009.01.042. PubMed: 19239892.

25. Araujo PR, Yoon K, Ko D, Smith AD, Qiao M et al. (2012) Before It Gets Started: Regulating Translation at the 5'UTR, compilor. Funct. Genomics: 2012. p. 475731

26. Anderson MA, Gusella JF (1984) Use of cyclosporin A in establishing Epstein-Barr virus-transformed human lymphoblastoid cell lines. In Vitro 20: 856-858. doi:10.1007/BF02619631. PubMed: 6519667.

27. Suzuki T, Inagaki H, Yamakuni T, Nagatsu T, Ichinose H (2002) Enhanced expression of GTP cyclohydrolase I in V-1-overexpressing PC12D cells. Biochem Biophys Res Commun 293: 962-968. doi: 10.1016/S0006-291X(02)00343-1. PubMed: 12051753.

28. Hirayama K, Shimoji M, Swick L, Meyer A, Kapatos G (2001) Characterization of GTP cyclohydrolase I gene expression in the human neuroblastoma SKN-BE(2)M17: enhanced transcription in response to CAMP is conferred by the proximal promoter. J Neurochem 79: 576-587. PubMed: 11701761

29. Inagaki H, Ohye T, Suzuki T, Segawa M, Nomura $Y$ et al. (1999) Decrease in GTP cyclohydrolase I gene expression caused by inactivation of one allele in hereditary progressive dystonia with marked diurnal fluctuation. Biochem Biophys Res Commun 260: 747-751. doi: 10.1006/bbrc.1999.0976. PubMed: 10403837.

30. lacono M, Mignone F, Pesole G (2005) UAUG and uORFs in human and rodent 5'untranslated mRNAs. Gene 349: 97-105. doi:10.1016/ j.gene.2004.11.041. PubMed: 15777708.

31. Liu L, Dilworth D, Gao L, Monzon J, Summers A et al. (1999) Mutation of the CDKN2A 5'UTR creates an aberrant initiation codon and predisposes to melanoma. Nat Genet 21: 128-132. doi:10.1038/5082. PubMed: 9916806.

32. Lukowski SW, Bombieri C, Trezise AE (2011) Disrupted posttranscriptional regulation of the cystic fibrosis transmembrane conductance regulator (CFTR) by a 5'UTR mutation is associated with a CFTR-related disease. Hum Mutat 32: E2266-E2282. doi:10.1002/ humu.21545. PubMed: 21837768

33. Niesler B, Flohr T, Nöthen MM, Fischer C, Rietschel M et al. (2001) Association between the 5'UTR variant $\mathrm{C} 178 \mathrm{~T}$ of the serotonin receptor gene HTR3A and bipolar affective disorder. Pharmacogenetics 11: 471-475. doi:10.1097/00008571-200108000-00002. PubMed: 11505217. 